\title{
Changes in the Human Skin Microbiome Over One Year's Time
}

\author{
${ }^{1,2}$ Richard W. Hyman, ${ }^{1}$ Farbod Babrzadeh, \\ ${ }^{1}$ Curtis Palm, ${ }^{1}$ Chunlin Wang, ${ }^{1}$ Marilyn Fukushima and ${ }^{1,2,3}$ Ronald W. Davis \\ ${ }^{1}$ Stanford Genome Technology Center, 855 S California Avenue, Palo Alto, CA 94304, USA \\ ${ }^{2}$ Department of Biochemistry, \\ ${ }^{3}$ Department of Genetics, \\ Stanford University College of Medicine, Stanford, CA 94305, USA
}

\begin{abstract}
Human skin comprises a large number of distinguishable ecological niches. To describe fully the human skin microbiome, it will be necessary to identify the bacteria in each niche and to distinguish the commensal bacteria from the temporary residents. To contribute to the description of the human skin microbiome and employing a gene-based technology, we have identified the bacteria in two niches: the front and back of the base of the neck and over the course of one year. There were 50 volunteers and a total of 232 neck skin swabs. Roche 454 Tag pyrosequencing was employed to sequence a short hypervariable sequence region (V6) of the $16 \mathrm{~S}$ ribosomal RNA gene. To identify the bacteria corresponding to the front and back of the neck for each volunteer, the "Classifier" software in the "Pyrosequencing" section of the Ribosomal Database Project was employed. The bacteria on virtually all 232 neck skin swabs were classified into bacterial Class. The skin microbiome of these two niches was composed principally of a mixture of five Classes of bacteria: Actinobacteria, Alphaproteobacteria, Bacilli, Betaproteobacteria and Gammaproteobacteria. The fraction of each Class could change over time. We could not distinguish the skin microbiome from the front of the base of the neck from the back of the base of the neck. At these two positions, we could not distinguish the male from the female skin microbiome. The principal variable was the time point. We concluded that the skin microbiome at the front and back of the base of the neck was composed principally of a mixture of five Classes of bacteria. The proportion of each Class could change over time.
\end{abstract}

Keywords: Bacteria, Skin, Human Microbiome, Time

\section{INTRODUCTION}

Human skin is a large organ with a multitude of distinguishable niches in contact with the external environment. In order to delineate the entire human skin microbiome, it will be necessary to identify the microbes in every niche, as a function of time and with people living in different geographical areas (Peterson et al., 2009). An excellent start has been made (Grice and Segre, 2011; Kong, 2011; HMPC, 2012).

Palo Alto, California, U.S.A., has a mild climate. However, that climate does change with the seasons. The season is part of the interactive environment of the skin bacteria and might have a significant impact on the Corresponding Author: Richard W. Hyman, Stanford Genome Technology Center, 855 S California Avenue, Palo Alto, CA 94304, USA quantitative composition of the skin microbiome. To investigate this possibility, we have identified the bacteria on two human skin niches (the front and back of the base of the neck) for fifty volunteers and over the course of one year.

\section{MATERIALS AND METHODS}

\subsection{Human Subjects}

Volunteers were recruited under a protocol approved by the Stanford University Institutional Review Board. All volunteers were healthy adults and gave written informed consent. Anyone who took antibiotics during the previous three months or had a significant underlying 
medical condition was ineligible to volunteer for this study. In total, there were 50 volunteers (Table 1). Forty volunteers were enrolled at the first time point (February, 2010; Table 1A). An additional 10 volunteers were enrolled at the second time point (July, 2010; Table 1B). Although this was their first swab, we gave their swabs the designation " 2 " (for the time point) to keep the focus on the time point. No new volunteers were accepted at the third time point (February, 2011). The volunteers were not asked to change any part of their routine: e.g., neither their standard hygiene procedures nor the clothing that they chose to wear. This point may be important because, for example, Staudinger et al. (2011) demonstrated that the use of facial powder significantly increased the diversity of the human forehead skin microbiome. We have previously published the results from the first time point, albeit in a very different form (Hyman et al., 2012). We included those results here for the purpose of comparisons.

\subsection{Amplifying and Purifying the V6 DNAs}

Each volunteer took her/his own swabs from the base of the front of the neck (overlaying the suprasternal notch) and the base of the back of the neck (overlaying the posterior cervical vertebrae: the nape, below the hair line) (Hyman et al., 2012). Total DNA was isolated from each front and back neck swab employing a Qiagen DNeasy Blood and Tissue Kit. The total DNA was dialyzed and concentrated by the use of Amicon Ultra Centrifugal Filters (Millipore Corp). For PCR amplification of the V6 region of the $16 \mathrm{~S}$ ribosomal RNA gene (rDNA), the forward and reverse primers were from Dethlefsen et al. (2008). Five identical reactions were run in parallel for each template. The PCR conditions were from Hyman et al. (2005). Following amplification, the five identical reactions for each template were pooled. The V6 DNA was purified by gel electrophoresis. We have employed Qiagen DNeasy Blood and Tissue Kits, Amicon Ultra Centrifugal Filters, PCR and purification of the amplicons by gel electrophoresis in previously reported experiments without problems of environmental contamination (Hyman et al., 2012; 2005).

\subsection{Pyrosequencing (Roche 454 Life Sciences)}

For the first time point only (February, 2010), the front and back amplicons for each volunteer shared the same bar code (Hyman et al., 2012). Therefore, the combined front V6s were pyrosequenced separately from the back V6s. For the second time point, the front and back V6s had different barcodes (Wang et al., 2012), so they were combined before pyrosequencing, as was also the case for the V6s for the third time point.
Table 1. Volunteers

\begin{tabular}{|c|c|c|}
\hline Volunteer ID & Male/Female & Long hair in back \\
\hline \multicolumn{3}{|c|}{ A. Volunteers enrolled in February, 2010} \\
\hline 01 & M & \\
\hline 02 & M & \\
\hline 03 & M & \\
\hline 04 & $\mathrm{~F}$ & \\
\hline 05 & $\mathrm{M}$ & \\
\hline 06 & M & \\
\hline 07 & $\mathrm{~F}$ & $\mathrm{Y}$ \\
\hline 08 & $\mathrm{~F}$ & $\mathrm{Y}$ \\
\hline 09 & $\mathrm{~F}$ & $\mathrm{Y}$ \\
\hline 10 & $\mathrm{~F}$ & $\mathrm{Y}$ \\
\hline 11 & $\mathrm{~F}$ & $\mathrm{Y}$ \\
\hline 12 & M & \\
\hline 13 & M & \\
\hline 14 & M & \\
\hline 15 & M & \\
\hline 16 & M & \\
\hline 17 & M & \\
\hline 18 & M & \\
\hline 19 & M & $\mathrm{Y} / \mathrm{N}$ \\
\hline 20 & $\mathrm{~F}$ & $\mathrm{Y}$ \\
\hline 21 & M & \\
\hline 22 & M & \\
\hline 23 & $\mathrm{~F}$ & $\mathrm{Y}$ \\
\hline 24 & M & \\
\hline 25 & $\mathrm{M}$ & \\
\hline 26 & $\mathrm{~F}$ & \\
\hline 27 & $\mathrm{M}$ & \\
\hline 28 & M & \\
\hline 29 & $\mathrm{~F}$ & \\
\hline 30 & M & \\
\hline 31 & M & \\
\hline 32 & $\mathrm{M}$ & \\
\hline 33 & $\mathrm{~F}$ & $\mathrm{Y}$ \\
\hline 34 & $\mathrm{M}$ & \\
\hline 35 & M & \\
\hline 36 & $\mathrm{~F}$ & \\
\hline 37 & $\mathrm{M}$ & \\
\hline 38 & M & \\
\hline 39 & $\mathrm{M}$ & \\
\hline 40 & $\mathrm{~F}$ & $\mathrm{Y}$ \\
\hline
\end{tabular}

\section{B. Volunteers enrolled in July, 2010}

$\begin{array}{lll}\text { Volunteer ID } & \text { Male/Female } & \text { Long hair in back } \\ 51 & \mathrm{M} & \\ 57 & \mathrm{~F} & \mathrm{Y} \\ 58 & \mathrm{~F} & \mathrm{Y} \\ 63 & \mathrm{~F} & \\ 66 & \mathrm{~F} & \\ 70 & \mathrm{~F} & \mathrm{Y} \\ 71 & \mathrm{M} & \mathrm{Y} \\ 75 & \mathrm{~F} & \mathrm{Y} \\ 76 & \mathrm{~F} & \\ 82 & \mathrm{~F} & \\ \mathrm{M}=\text { Male. } & \mathrm{F}=\text { Female. } \mathrm{Y}=\text { yes. } \mathrm{Y} / \mathrm{N}=\text { intermediate long hair } \\ \text { in back } & \end{array}$


Our detailed pyrosequencing procedures were published previously (Hyman et al., 2012).

The sequence reads were sorted by barcode and, thereby, assigned to the front or back of a specific volunteer. Then, the pyrosequencing reads were stripped of extraneous sequences. A data set was created that consisted of each unique sequence obtained for that sample and the number of times that sequence was represented in the sample. To identify the bacteria corresponding to the front and back of the neck for each volunteer, the "Classifier" software (Wang et al., 2007) in the "Pyrosequencing" section of the Ribosomal Database Project (RDP) was employed (Cole et al., 2009). Only reads that could be classified were considered further. There were reads too short to be classified. For example, for 3F, these short reads averaged $1.2 \%(\mathrm{n}=35)$ of the total. The DECIPHER software was employed to identify chimeras (Wright et al., 2012). In virtually all cases, the software identified the bacteria by Class. A very few reads in some sets were identified not by Class but by genus: e.g., TM7. In these cases, the reads were subsumed into Class. In a minority of cases, the software also identified the bacteria by Order. Actinobacteria were divided into Subclasses rather than Order. These were subsumed into Order.

\subsection{Analyses}

Chao1 (Colwell and Coddington, 1994; Hughes et al., 2001), Principal Component Analysis (PCA) and Shannon Diversity Index (SDI) analyses employed the QIIME, "Quantitative Insights into Microbial Ecology", software (Caporaso et al., 2010) with UniFrac distances (Lozupone et al., 2011). The SDI (Shannon, 1948) was calculated for the microbiome of each neck swab (http://math.hws.edu/javamath/ryan/DiversityTest.html).

\section{RESULTS AND DISCUSSION}

From the 50 volunteers, we achieved data for a total of 232 neck swabs, divided between the front (115) and the back (117) of the base of the neck (Table 1). We have front and back swabs from three time points for 29 volunteers; two time points for 11 volunteers; and only one time point for 10 volunteers. The three time points were designated as 1,2 and 3, respectively. Bacteria were identified by 454 Tag pyrosequencing of a short hypervariable sequence region (V6) of the $16 \mathrm{~S}$ ribosomal RNA gene (Huse et al., 2008).

\subsection{Class}

In sampling an ecological niche, cost and time considerations prevent exhaustive sequencing. Therefore, statistical tests have been derived that indicate the closeness to saturation. Chaol is one such test (Colwell and Coddington, 1994). The results of Chaol analyses of the data are shown in Fig. 1 and demonstrate that the data are not close to saturation (see Discussion).

The bacteria on all 232 neck skin swabs were classified into Class. The complete data for all 232 swabs are presented on the Stanford Genome Technology Center (SGTC) web site (Table S1; http://med.stanford.edu/sgtc/research/skin_microbio me.html). Table 2 presents examples of the bacterial identifications. To make the data visually comprehensible, only those bacteria supported by, at least, $1 \%$ of the reads are reported in the tables. The overall average per swab $(n=232)$ of the total percent of the bacteria supported by more than $1 \%$ of the reads was $98.2+/-1.0 \%$ (Table 2 ). We concluded that this very high percentage demonstrated that little information was lost when the focus was on those bacteria supported by, at least, $1 \%$ of the reads.

Fifteen Classes of bacteria were identified (Table 3). The presence of five bacterial Classes was supported by more than $1 \%$ of the reads on virtually all of the swabs, albeit in very different amounts: Actinobacteria, Alphaproteobacteria, Bacilli, Betaproteobacteria and Gammaproteobacteria (Table 3). Gammaproteobacteria were supported by the most reads for $85 \%$ of the swabs, followed by Actinobacteria (10\%) and Bacilli (5\%). On the second and third time points, Flavobacteria and Sphingobacteria appear on virtually all swabs, also in very different amounts. On the other hand, the presence of some bacteria was supported by more than $1 \%$ of the reads only peripatetically. Bacteroidia were found on only 11 swabs (4.7\%) and only in small amounts, as were Deinococci (one swab, 0.4\%), Deltaproteobacteria (3 swabs; 1.3\%), Fusobacteria (5 swabs; 2.2\%) and Verrucomicrobia (one swab; 0.4\%). Cyanobacteria were not found on swab 3, while Chloroplasts were found only on swab 3. The presence of Proteobacteria were supported by reads in the amounts of Gammaproteobacteria $\gg$ Betaproteobacteria > Alphaproteobacteria. The blank spaces in the data tables (Table 2 and Table S1; http://med.stanford.edu/sgtc/research/skin_microbiom e.html) signify that that particular bacterium's presence was supported by $<1 \%$ of the sequence reads, if present at all. As one example, there were three blank spaces for Bacilli in the complete data table (Table $\mathrm{S} 1$; http://med.stanford.edu/sgtc/research/skin_microbiom e.html). However, there were sequence reads supporting the presence of Bacilli on all three of those swabs: $33-1 \mathrm{~F}$, $0.43 \%$ of the reads; $33-1 \mathrm{~B}, 0.70 \%$; and $34-1 \mathrm{~F}, 0.75 \%$. Analogously, there were reads supporting the presence of 
Alphaproteobacteria and Betaproteobacteria on all swabs, albeit sometimes at a frequency of $<1 \%$. As additional examples for what was not reported in Table 2, for 01-3F, the presence of Deinococci was supported by three reads $(0.41 \%)$ and the presence of Deltaproteobacteria was supported by four reads $(0.54 \%)$.

Analyses were undertaken for four variables: location (front versus back), gender (male versus female), hair length in back (long hair versus short hair) and time point. For an analysis of the variable of location, we calculated the average percent per swab (front and back separately) for each of the five major bacteria at each of the three time points. The results of these calculations are presented in Fig. 2. For all five bacterial Classes, there was no statistically significant difference between the paired front and back swabs. As examples, for Gammaproteobacteria, $1 \mathrm{~F}$ was not statistically significantly different from $1 \mathrm{~B}(\mathrm{p}=0.88) ; 2 \mathrm{~F}$ was not statistically significantly different from $2 \mathrm{~B}(\mathrm{p}=0.62)$; and $3 \mathrm{~F}$ was not statistically significantly different from $3 B(p=0.38)$.

Table 2. Examples of Class data. The bacterial Class composition as percent of four skin swabs as a function of time and location. Only those bacterial Classes supported by $>1 \%$ of the sequence reads appear in the Table. The skin swabs were from volunteers $01,02,03$ and 04 . Time points 1,2 and $3 . F=$ front of the base of the neck. $\mathrm{B}=$ back of the base of the neck

\begin{tabular}{|c|c|c|c|c|c|c|c|c|c|c|c|c|c|}
\hline$(\%)$ & $\begin{array}{l}\text { Class } \\
\text { volunteer } \\
\text { ID }\end{array}$ & $\begin{array}{l}\text { Actinob } \\
\text { acteria }\end{array}$ & $\begin{array}{l}\text { Alphaprot } \\
\text { eobacteria }\end{array}$ & Bacilli & $\begin{array}{l}\text { Betaproteo } \\
\text { bacteria }\end{array}$ & $\begin{array}{l}\text { Chlor } \\
\text { oplast }\end{array}$ & Clostridia & $\begin{array}{l}\text { Cyanob } \\
\text { acteria }\end{array}$ & $\begin{array}{l}\text { Flavob } \\
\text { acteria }\end{array}$ & $\begin{array}{l}\text { Gammap } \\
\text { roteobacteria }\end{array}$ & $\begin{array}{l}\text { Sphingo } \\
\text { bacteria }\end{array}$ & $\begin{array}{l}\text { Total } \\
(\%)\end{array}$ & $\begin{array}{l}\text { Total } \\
\text { reads }\end{array}$ \\
\hline Winter & $01-1 \mathrm{~F}$ & 5.8 & 1.3 & 27.1 & 1.3 & & & & & 63.4 & & 98.9 & 8036 \\
\hline Summer & $01-2 \mathrm{~F}$ & 8.6 & 3.4 & 10.9 & 9.2 & & 1.2 & 1.3 & 4.7 & 58.2 & & 97.5 & 595 \\
\hline Winter & $01-3 \mathrm{~F}$ & 7.8 & 8.3 & 10.5 & 17.1 & & 1.0 & & 9.7 & 36.7 & 6.0 & 97.1 & 735 \\
\hline Winter & 01-1B & 9.9 & 1.4 & 3.9 & 1.7 & & & & & 81.5 & & 98.4 & 7113 \\
\hline Summer & $01-2 B$ & 7.6 & 4.2 & 3.0 & 11.6 & & 1.0 & 1.0 & 6.3 & 62.7 & 2.3 & 99.7 & 432 \\
\hline \multirow[t]{15}{*}{ Winter } & $01-3 B$ & 7.1 & 8.7 & 5.5 & 17.5 & & & & 9.2 & 42.9 & 5.7 & 96.6 & 750 \\
\hline & $02-1 \mathrm{~F}$ & 22.8 & 2.7 & 3.9 & 1.3 & & & & & 67.9 & & 98.6 & 6052 \\
\hline & $02-2 \mathrm{~F}$ & 17.2 & 2.9 & 15.2 & 7.4 & & & 2.5 & 3.1 & 49.2 & 2.0 & 99.5 & 551 \\
\hline & $02-3 \mathrm{~F}$ & 26.2 & 2.9 & 12.6 & 7.7 & & & & 4.7 & 42.2 & 2.4 & 98.7 & 803 \\
\hline & $02-1 \mathrm{~B}$ & 18.3 & 2.6 & 2.4 & 1.3 & & & & & 74.7 & & 99.3 & 3405 \\
\hline & $02-2 B$ & 20.0 & 2.4 & 4.9 & 7.7 & & & 1.4 & 4.9 & 55.9 & 2.0 & 99.2 & 506 \\
\hline & $02-3 \mathrm{~B}$ & 21.2 & 7.0 & 5.5 & 9.8 & 1.1 & & & 6.8 & 43.9 & 3.5 & 98.8 & 711 \\
\hline & $03-1 \mathrm{~F}$ & 6.2 & 1.3 & 3.7 & 1.5 & & & & & 85.6 & & 98.3 & 2752 \\
\hline & 03-1B & 12.8 & 1.2 & 4.6 & & & & & & 79.2 & & 97.8 & 1923 \\
\hline & $04-1 \mathrm{~F}$ & no & data & & & & & & & & & & \\
\hline & $04-2 \mathrm{~F}$ & 5.9 & 3.3 & 4.8 & 9.6 & & 1.5 & & 5.6 & 63.8 & 2.8 & 97.3 & 539 \\
\hline & $04-3 \mathrm{~F}$ & 4.9 & 3.7 & 3.2 & 11.7 & & & & 2.5 & 68.5 & 2.2 & 96.7 & 596 \\
\hline & 04-1B & no & data & & & & & & & & & & \\
\hline & $04-2 B$ & 17.8 & 3.8 & 8.5 & 5.7 & & 1.0 & & 5.9 & 53.6 & 1.4 & 97.7 & 422 \\
\hline & $04-3 \mathrm{~B}$ & 12.2 & 2.4 & 7.5 & 9.3 & & 1.5 & & 7.2 & 55.8 & 3.2 & 99.1 & 787 \\
\hline
\end{tabular}

Table 3. Bacterial Class total percentages. The percent of the swabs with the bacterial Class supported by $>1 \%$ of the reads as a function of time and location. Time points 1,2 and $3 . \mathrm{F}=$ front of the base of the neck. $\mathrm{B}=$ back of the base of the neck

\begin{tabular}{|c|c|c|c|c|c|c|c|c|c|}
\hline & 1 & 2 & 3 & $1 \mathrm{~F}$ & $2 \mathrm{~F}$ & $3 \mathrm{~F}$ & $1 \mathrm{~B}$ & $2 \mathrm{~B}$ & $2 \mathrm{~B}$ \\
\hline & Winter & Summer & Winter & Winter & Summer & Winter & Winter & Summer & Winter \\
\hline Class & Total & Total & Total & Front & Front & Front & Back & Back & Back \\
\hline Actinobacteria & 98.7 & 100.0 & 100.0 & 100.0 & 100.0 & 100.0 & 97.4 & 100.0 & 100.0 \\
\hline Alphaproteobacteria & 87.2 & 96.5 & 100.0 & 84.6 & 97.6 & 100.0 & 89.7 & 95.3 & 100.0 \\
\hline Bacilli & 93.6 & 100.0 & 100.0 & 92.3 & 100.0 & 100.0 & 94.9 & 100.0 & 100.0 \\
\hline Bacteroidia & 0.0 & 8.2 & 7.1 & 0.0 & 11.9 & 11.8 & 0.0 & 4.7 & 2.8 \\
\hline Betaproteobacteria & 91.0 & 100.0 & 100.0 & 94.9 & 100.0 & 100.0 & 87.2 & 100.0 & 100.0 \\
\hline Chloroplast & 0.0 & 0.0 & 44.3 & 0.0 & 0.0 & 38.2 & 0.0 & 0.0 & 50.0 \\
\hline Clostridia & 2.6 & 43.5 & 64.3 & 2.6 & 50.0 & 73.5 & 2.6 & 37.2 & 55.5 \\
\hline Cyanobacteria & 6.4 & 38.8 & 0.0 & 5.1 & 35.7 & 0.0 & 7.7 & 41.9 & 0.0 \\
\hline Deinococci & 0.0 & 0.0 & 1.4 & 0.0 & 0.0 & 2.9 & 0.0 & 0.0 & 0.0 \\
\hline Deltaproteobacteria & 0.0 & 0.0 & 4.3 & 0.0 & 0.0 & 2.9 & 0.0 & 0.0 & 5.6 \\
\hline Flavobacteria & 44.9 & 98.8 & 100.0 & 43.6 & 100.0 & 100.0 & 46.2 & 97.7 & 100.0 \\
\hline Fusobacteria & 0.0 & 2.4 & 1.4 & 0.0 & 4.8 & 2.9 & 0.0 & 0.0 & 0.0 \\
\hline Gammaproteobacteria & 98.7 & 100.0 & 100.0 & 100.0 & 100.0 & 100.0 & 97.4 & 100.0 & 100.0 \\
\hline Sphingobacteria & 48.7 & 82.4 & 100.0 & 48.7 & 78.6 & 100.0 & 48.7 & 86.0 & 100.0 \\
\hline Verrucomicrobia & 0.0 & 0.0 & 1.4 & 0.0 & 0.0 & 0.0 & 0.0 & 0.0 & 2.8 \\
\hline Total swabs & 77.0 & 85.0 & 70.0 & 39.0 & 42.0 & 34.0 & 38.0 & 43.0 & 36.0 \\
\hline
\end{tabular}


Richard W. Hyman et al. / American Journal of Microbiology 3 (2): 18-30, 2012

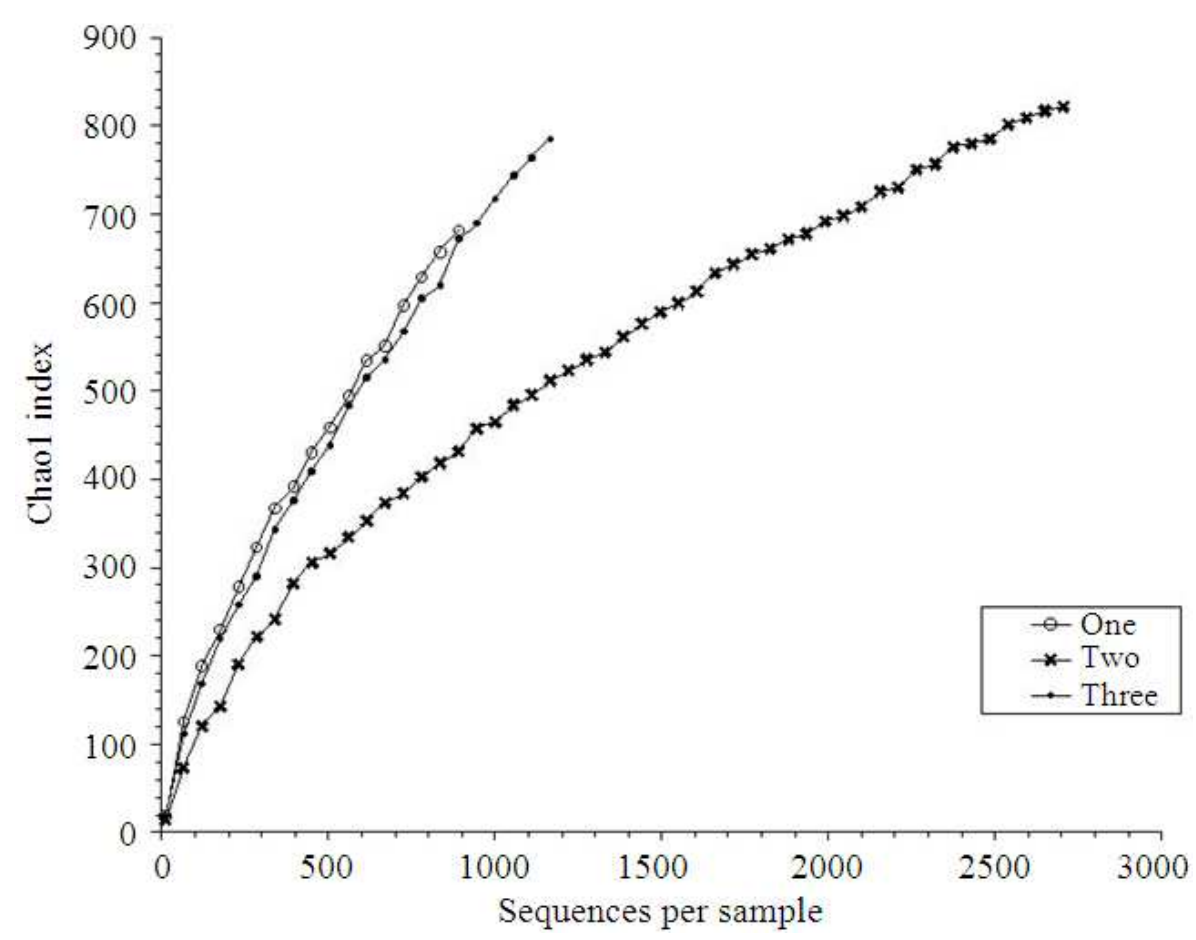

Fig. 1. Chao1 analysis of the data from the three time points. Time point 1, open circles; time point 2, crosses; and time point 3, closed circles

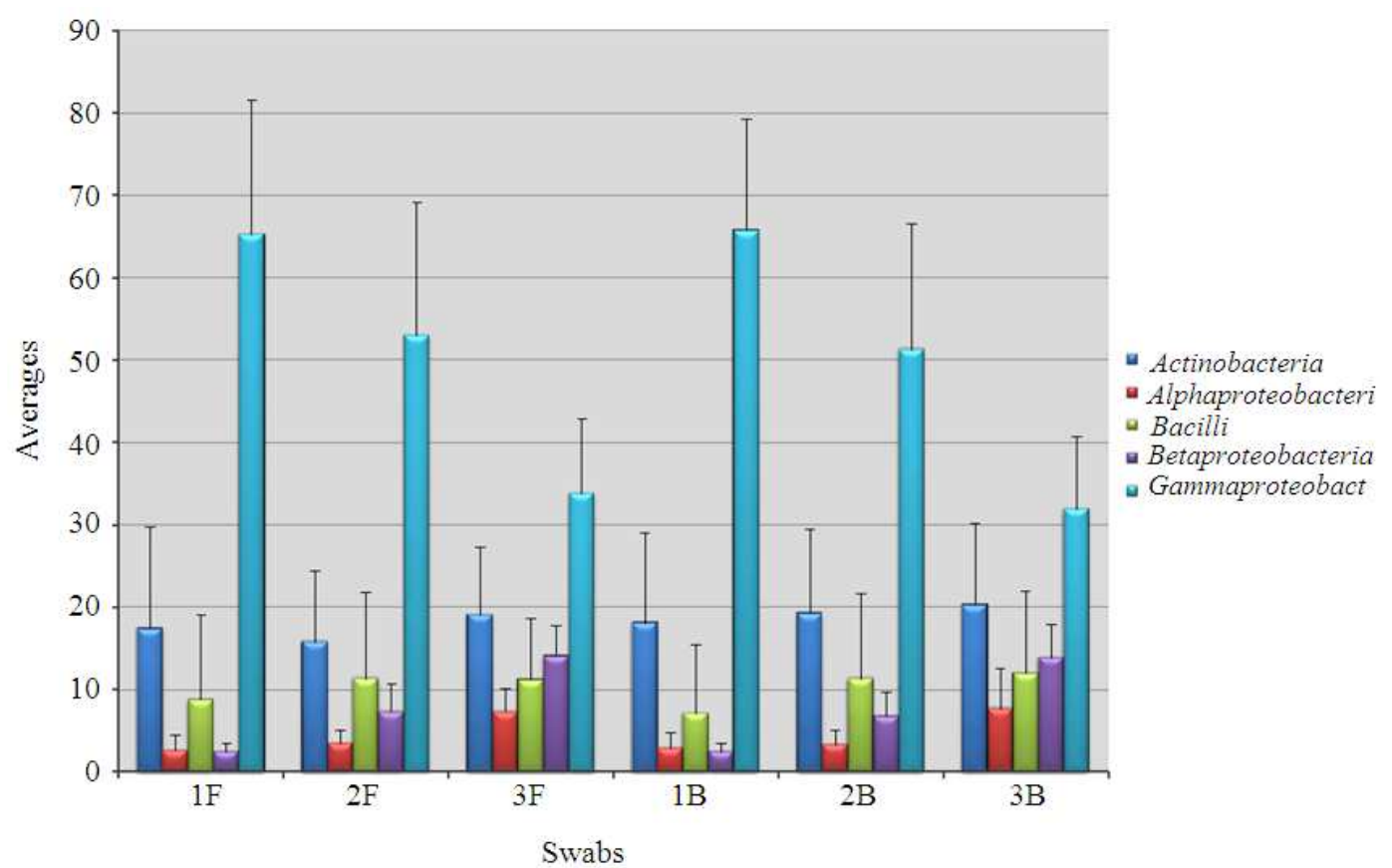

Fig. 2. Class time course. The average percentage and standard deviation of each of five bacterial Classes as a function of time and location. Time points 1, 2, and 3. Front (F) and back (B) of the base of the neck. Dark blue, Actinobacteria; red, Alphaproteobacteria; green, Bacilli; purple, Betaproteobacteria; light blue, Gammaproteobacteria 
In addition, Principal Coordinate Analysis (PCA) did not distinguish Front from Back (Fig. S1; http://med.stanford.edu/sgtc/research/skin_microbiom e.html).

For an analysis of the variable of gender, we compared the skin microbiome at the base of the neck of the 27 males to that of the 12 females. None of the gender comparisons yielded statistically significant differences (data not shown). As one example, we compared the percents of Actinobacteria and Gammaproteobacteria for men and women on swab $1 \mathrm{~F}$. There were no statistically significant differences $(\mathrm{p}=0.15$ and 0.12 , respectively). In addition, PCA did not distinguish females from males (Fig. S1; http://med.stanford.edu/sgtc/research/skin_microbiom e.html).

Thirteen women had long hair in back and six women had short hair in back. To determine the effect of long hair in back on the skin microbiome at the base of the back of the neck, we compared the percents of Actinobacteria and Gammaproteobacteria for women with and without long hair in back for swab 2B. The differences were not statistically significant $(p=0.70$ and 0.85 , respectively). In addition, PCA did not distinguish women with and without long hair in back (Fig. $\mathrm{S} 1$; http://med.stanford.edu/sgtc/research/skin_microbiom e.html).

Lastly, we undertook an analysis of the time points, which did produce statistically significant results. For example, $1 \mathrm{~F}$ was statistically significantly different from $2 \mathrm{~F}(\mathrm{p}<0.001)$ and $2 \mathrm{~F}$ was statistically significantly different from $3 \mathrm{~F}(\mathrm{p}<0.00001)$ and the same for the back swabs. PCA was undertaken for the variable of time point. The results are shown in Fig. 3. The time points clustered and $34 \%$ of the variation in P1 versus P2 and $\mathrm{P} 1$ versus $\mathrm{P} 3$ could be ascribed to time point.

Bacterial diversity was examined by calculating the widely used Shannon Diversity Index (SDI) for each swab (Shannon, 1948). For example, when only one bacterium is present, the SDI $=0$; there is no diversity. The SDI data are presented in Table 4, which also contains the average values and standard deviations for each group of swabs. There was no statistically significant difference between the average SDIs of $1 \mathrm{~F}$ $(1.37+/-0.36)$ and $1 \mathrm{~B}(1.38+/-0.29 ; \mathrm{p}=0.89), 2 \mathrm{~F}(1.95+/$ $0.37)$ and $2 \mathrm{~B}(1.94+/-0.33 ; \mathrm{p}=0.89)$ and $3 \mathrm{~F}(2.50+/-.22)$ and $3 \mathrm{~B}(2.46+/-0.16 ; \mathrm{p}=0.39)$. In addition, we were unable to distinguish the SDIs of males and females. As examples, the SDI of the male $(n=27)$ front swab $1 F$ was not statistically significant different from the female $(\mathrm{n}=12)$ front swab $1 F(\mathrm{p}=0.23)$. The SDI of the male $(n=24)$ back swab $2 B$ was not statistically significant different from the female $(n=18)$ back swab 2B $(p=0.46)$. When we compared the SDIs of the swabs as a function of time point, an interesting pattern emerged: the average SDIs of the time points were statistically different from each other. As examples, the average SDI of the front swabs from the first time point was statistically significantly different from the average SDI of the front swabs of the second time point $(p<0.00001)$. The average SDI of the front swabs from the second time point was statistically significantly different from the average SDI of the front swabs from the third time point $(p<0.00001)$. The analogous statistically significant differences hold true for the SDIs of the back swabs.

To investigate the change in diversity as a function of time in more detail, we determined that we had data for 129 transitions: e.g., from $01-1 \mathrm{~F}$ to $01-2 \mathrm{~F}$ and from $01-2 \mathrm{~F}$ to $01-3 \mathrm{~F}$ (Table S2; http://med.stanford.edu/sgtc/research/skin_microbiome. html). We considered a change in the percentage of reads supporting the presence of a bacterium of less than an absolute $10 \%$ as "no change", an arbitrary, but reasonable amount which we have employed previously (Hyman et al., 2012). For example, for the 01-1 F to $01-2 \mathrm{~F}$ transition, the percentage of reads supporting Gammaproteobacteria went from 63.4 to $58.2 \%$. For these numbers to register as a change, $01-2 \mathrm{~F}$ would have to be greater than $73.4 \%$ or less than $53.4 \%$. On the other hand, within the same transition, the percentage of reads supporting Bacilli went from 27.1 to $10.9 \%$. These numbers were different by an absolute $16.2 \%$. Therefore, there was a "change". With this definition, 29 of 129 transitions (23\%) register as "no change". An example is the $02-2 \mathrm{~F}$ to $02-3 \mathrm{~F}$ transition (Table

$\mathrm{S} 2$; http://med.stanford.edu/sgtc/research/skin_microbiome. html), where the largest change is for Actinobacteria, which went from 17.2 to $26.2 \%$, an absolute change of $9 \%$. There was no series of 01 -to-02-to-03 where there was no change. We considered a change of an absolute $20 \%$ or more as a large change: again, an arbitrary, but reasonable amount that we have employed previously (Hyman et al., 2012). There were 47 out of 129 transitions (36\%) that were more than an absolute $20 \%$. 
Richard W. Hyman et al. / American Journal of Microbiology 3 (2): 18-30, 2012

Table 4. Class SDI. The SDI was calculated from the bacterial Class data for each swab

\begin{tabular}{|c|c|c|c|c|c|c|}
\hline ID & Winter 1F & Summer 2F & Winter $3 \mathrm{~F}$ & Winter 1B & Summer 2B & Winter 3B \\
\hline$\overline{01}$ & 1.33 & 1.97 & 2.56 & 0.93 & 1.92 & 2.36 \\
\hline 02 & 1.27 & 2.18 & 2.19 & 1.11 & 1.98 & 2.34 \\
\hline 03 & 0.78 & & & 0.92 & & \\
\hline 04 & No data & 1.83 & 1.54 & No data & 2.05 & 2.10 \\
\hline 05 & 0.76 & 1.84 & 2.75 & 1.32 & 1.80 & 2.32 \\
\hline 06 & 0.94 & 1.74 & & 1.06 & 2.20 & \\
\hline 07 & 1.18 & 1.57 & & 1.39 & 1.70 & \\
\hline 08 & 0.89 & 1.74 & 2.42 & 0.88 & 1.80 & 2.25 \\
\hline 09 & 1.39 & 1.45 & 2.60 & 1.38 & 1.63 & 2.52 \\
\hline 10 & 0.78 & 1.73 & 2.40 & 1.27 & 1.87 & 2.53 \\
\hline 11 & 0.78 & 1.50 & 2.56 & 0.90 & 1.52 & 2.43 \\
\hline 12 & 1.45 & 1.61 & 2.63 & 1.02 & 1.75 & 2.38 \\
\hline 13 & 1.54 & 1.49 & 2.35 & 1.50 & 1.67 & 2.52 \\
\hline 14 & 1.28 & & & 1.27 & & \\
\hline 15 & 1.68 & 2.76 & 2.61 & 1.52 & 2.39 & 2.60 \\
\hline 16 & 1.33 & 2.20 & 2.65 & 1.47 & 1.99 & 2.63 \\
\hline 17 & 0.92 & 1.71 & & 1.03 & 1.74 & \\
\hline 18 & 1.41 & 1.65 & 2.37 & 1.59 & 1.91 & 2.25 \\
\hline 19 & 1.04 & 2.11 & & 1.43 & 1.93 & \\
\hline 20 & 1.01 & 2.15 & 2.40 & No data & 2.14 & 2.42 \\
\hline 21 & 1.42 & & & 1.64 & & \\
\hline 22 & 1.64 & 1.89 & 2.67 & 1.75 & 1.57 & 2.41 \\
\hline 23 & 1.04 & & & 1.43 & & \\
\hline 24 & 1.82 & 1.99 & 2.31 & 1.92 & 1.96 & 2.51 \\
\hline 25 & 1.65 & 2.12 & 2.54 & 1.65 & 2.22 & 2.49 \\
\hline 26 & 1.77 & 1.98 & 2.67 & 1.72 & 1.90 & 2.44 \\
\hline 27 & 1.63 & & 2.56 & 1.51 & & 2.52 \\
\hline 28 & 1.38 & 2.20 & 2.56 & 1.38 & 2.17 & 2.36 \\
\hline 29 & 1.65 & 1.60 & No data & 1.10 & 1.88 & 2.75 \\
\hline 30 & 1.63 & No data & 2.63 & 1.22 & 1.84 & 2.81 \\
\hline 31 & 1.86 & 1.98 & 2.44 & 1.89 & 1.37 & 2.48 \\
\hline 32 & 1.88 & 1.81 & 2.45 & 1.60 & 1.97 & 2.50 \\
\hline 33 & 1.01 & 2.00 & 2.63 & 0.96 & 1.68 & 2.23 \\
\hline 34 & 1.18 & 2.19 & 2.50 & 1.35 & 2.00 & 2.46 \\
\hline 35 & 1.73 & 1.93 & 2.34 & 1.71 & 1.85 & 2.40 \\
\hline 36 & 2.07 & & & 1.46 & & \\
\hline 37 & 1.88 & 1.84 & 2.56 & 1.81 & 1.56 & 2.63 \\
\hline 38 & 1.67 & 1.84 & 2.42 & 1.49 & 1.52 & 2.36 \\
\hline 39 & 1.06 & & & 1.20 & & \\
\hline 40 & 1.54 & 2.29 & No data & 1.79 & 2.30 & 2.38 \\
\hline 51 & & 1.76 & & & 1.75 & \\
\hline 57 & & 1.71 & 2.48 & & 2.12 & 2.61 \\
\hline 58 & & 1.89 & & & 2.13 & \\
\hline 63 & & 1.60 & & & 1.82 & \\
\hline 66 & & 1.61 & & & 1.56 & \\
\hline 70 & & 2.68 & 2.67 & & 2.70 & 2.67 \\
\hline 71 & & 2.73 & 2.55 & & 2.38 & 2.15 \\
\hline 75 & & 2.71 & 2.89 & & 2.75 & 2.66 \\
\hline 76 & & 2.91 & 2.40 & & 2.81 & 2.62 \\
\hline 82 & & 1.35 & 2.55 & & 1.49 & 2.60 \\
\hline No. swabs & 39 & 42 & 34 & 38 & 43.00 & 36.00 \\
\hline Average & 1.37 & 1.95 & 2.50 & 1.38 & 1.94 & 2.46 \\
\hline SD & 0.36 & 0.37 & 0.22 & 0.29 & 0.33 & 0.16 \\
\hline
\end{tabular}

No $=$ Number of; SD $=$ Standard Deviation 


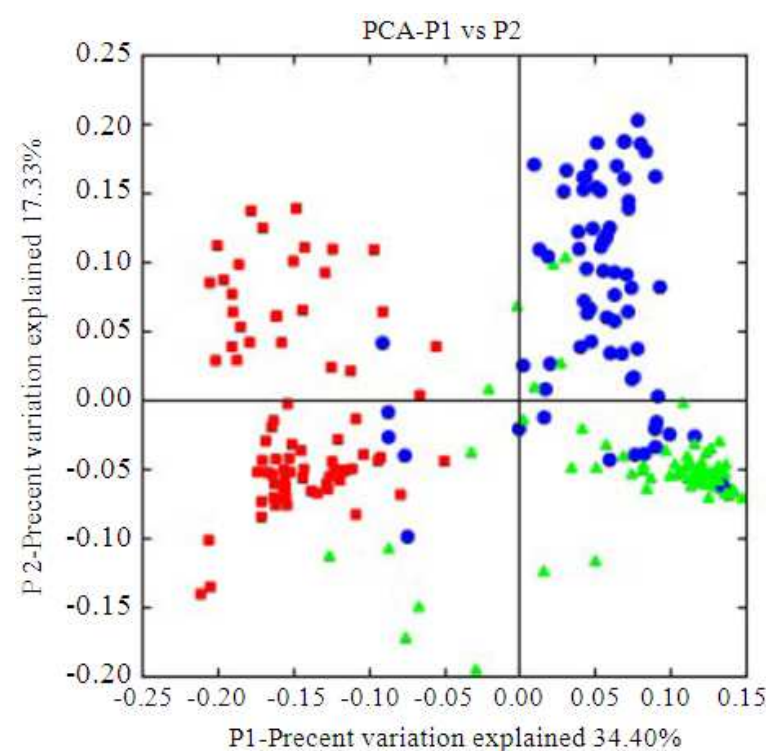

(a)

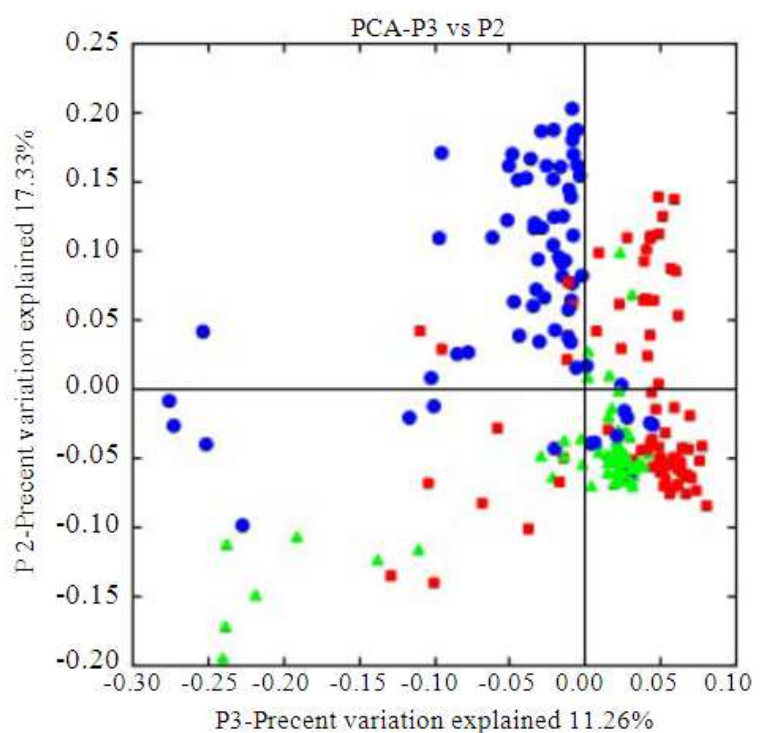

(b)

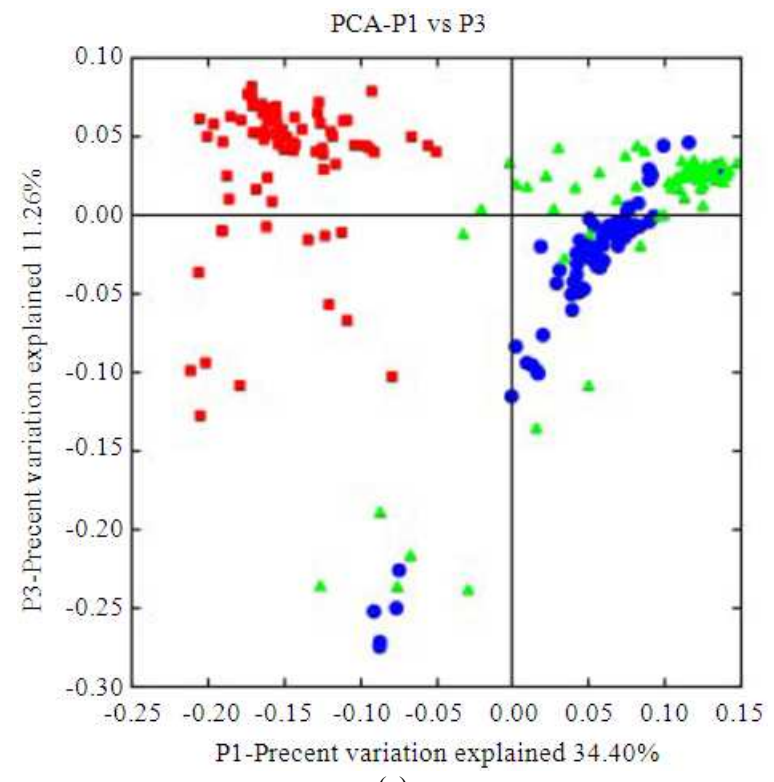

(c)

Fig. 3. PCA of time point. Time point 1, red squares; time point 2, green triangles; and time point 3, blue circles

There were three cases where there was more than an absolute $20 \%$ change in going from swab 1 to swab 2 to swab 3: e.g., 15-1F-to-15-2F-to-15-3F (Table S2; $\mathrm{http}: / /$ med.stanford.edu/sgtc/research/skin_microbiome.h tml). For this swab, the percentage of reads supporting the presence of Gammaproteobacteria went from 49.3to-17.4-to-28.0\%. There was no transition of greater than an absolute $30 \%$.
The 129 transitions were divided into four groups: 1F-to-2F, 2F-to-3F, 1B-to-2B and 2B-to-3B. The changes in the composition of the three most abundant bacterial Classes were examined individually for the four types of transitions (Table 5). The percent of Actinobacteria and Bacilli seldom changed (up or down), while the percent of Gammaproteobacteria decreased by more than 50\% in all four transitions (Table 5). 
Table 5. Changes in Class percent for four time transitions: $1 \mathrm{~F}$ to $2 \mathrm{~F}, 2 \mathrm{~F}$ to $3 \mathrm{~F}, 1 \mathrm{~B}$ to $2 \mathrm{~B}, 2 \mathrm{~B}$ to $3 \mathrm{~B}$. The average percent change, higher (Up), lower (Down), for four time transitions

\begin{tabular}{lrrrr}
\hline Transition & No. & Up & Down & No change \\
\hline 1F to 2F & 31 & & & \\
Actinobacteria & & 6.5 & 12.9 & 80.6 \\
Bacilli & & 19.4 & 6.5 & 74.2 \\
Gammaproteobacteria & & 6.5 & 51.6 & 41.9 \\
2F to 3F & 32 & & & \\
Actinobacteria & & 15.6 & 0.0 & 84.4 \\
Bacilli & 3.1 & 6.3 & 90.6 \\
Gammaproteobacteria & & 6.3 & 68.8 & 25.0 \\
1B to 2B & 31 & & & \\
Actinobacteria & & 16.1 & 9.7 & 74.2 \\
Bacilli & 19.4 & 3.2 & 77.4 \\
Gammaproteobacteria & & 6.5 & 58.1 & 35.5 \\
2B to 3B & 35 & & & \\
Actinobacteria & & 14.3 & 5.7 & 80.0 \\
Bacilli & 8.6 & 5.7 & 85.7 \\
Gammaproteobacteria & & 0.0 & 74.3 & 25.7 \\
\hline Tilm poln
\end{tabular}

Time points 1,2 and $3 . \mathrm{F}=$ front of the base of the neck. $\mathrm{B}=$ back of the base of the neck

\subsection{Order}

The bacteria on 67 neck skin swabs $(29 \%$ of the total swabs) were classified further into Order: 27 (40\%) front swabs and 40 (60\%) back swabs (Table S3; http://med.stanford.edu/sgtc/research/skin_microbiome.ht $\mathrm{ml}$ ). Presumably, our data and the RDP software were the determinants for which samples the bacteria could be identified by Order. As for the Class data, to make the Order data visually comprehensible, only those bacterial Orders supported by, at least, $1 \%$ of the reads are reported (Table S3; http://med.stanford.edu/sgtc/research/skin_microbiome.ht $\mathrm{ml}$ ). Thereby, 31 Orders of bacteria were identified, compared to 15 Classes of bacteria. (More Orders than Classes were expected because each Class is composed of more than one Order). Only one bacterial Order, Actinobacteridae, was supported by, at least, $1 \%$ of the reads on all of the 67 swabs (Table 6).

Table 6. Bacterial Order total percentages. The percent of the swabs with the bacterial Order supported by $>1 \%$ of the reads as a function of time and location

\begin{tabular}{|c|c|c|c|c|c|c|c|c|c|}
\hline Order & $\begin{array}{l}\text { Winter } \\
\text { Total }\end{array}$ & $\begin{array}{l}\text { Summer } \\
\text { Total }\end{array}$ & $\begin{array}{l}\text { Winter } \\
\text { Total }\end{array}$ & $\begin{array}{l}\text { Winter } \\
1 \mathrm{~F}\end{array}$ & $\begin{array}{l}\text { Summer } \\
2 \mathrm{~F}\end{array}$ & $\begin{array}{l}\text { Winter } \\
3 \mathrm{~F}\end{array}$ & $\begin{array}{l}\text { Winter } \\
1 \mathrm{~B}\end{array}$ & $\begin{array}{l}\text { Summer } \\
\text { 2B }\end{array}$ & $\begin{array}{l}\text { Winter } \\
\text { 3B }\end{array}$ \\
\hline$\overline{\text { Acidimicrobidae }}$ & 0.0 & 2.6 & (0) 0.0 & 0.0 & $(0)$ & 0.04 .8 & $(0)$ & & \\
\hline Actinobacteridae & 100.0 & 100.0 & (100) & 100.0 & 100.0 & $(100)$ & 100.0 & 100.0 & $(100)$ \\
\hline Aeromondales & 0.0 & 57.9 & (33.3) & 0.0 & 70.6 & $(50)$ & 0.0 & 47.6 & $(0)$ \\
\hline Alteromonadales & 76.9 & 60.5 & (100) & 62.5 & 64.7 & (100) & 83.3 & 61.9 & (100) \\
\hline Bacillales & 96.2 & 100.0 & (100) & 100.0 & 100.0 & (100) & 94.4 & 100.0 & $(100)$ \\
\hline Bacteroidales & 0.0 & 5.3 & (33.3) & 0.0 & 5.9 & $(50)$ & 0.0 & 4.8 & $(0)$ \\
\hline Bdellovibrionales & 0.0 & 2.6 & (0) 0.0 & 5.9 & (0) & 0.00 .0 & $(0)$ & & \\
\hline Burkholderiales & 80.8 & 100.0 & (100) & 87.5 & 100.0 & $(100)$ & 77.8 & 100.0 & $(100)$ \\
\hline Campylobacterales & 0.0 & 2.6 & (0) 0.0 & 5.9 & (0) & 0.00 .0 & $(0)$ & & \\
\hline Caulobacterales & 3.8 & 50.0 & (66.6) & 12.5 & 58.8 & $(100)$ & 0.0 & 42.9 & (0) \\
\hline Chloroplast & 7.7 & 71.1 & (66.6) & 12.5 & 76.5 & (100) & 5.6 & 66.7 & (0) \\
\hline Chromatiales & 73.1 & 78.9 & (0) 62.5 & 76.5 & $(0)$ & 77.8 & 81.0 & $(0)$ & \\
\hline Clostridiales & 0.0 & 52.6 & $(66.6)$ & 0.0 & 41.2 & $(100)$ & 0.0 & 61.9 & (0) \\
\hline Coriobacteridae & 0.0 & 2.6 & (0) 0.0 & 5.9 & (0) & 0.00 .0 & (0) & & \\
\hline Enterobacteriales & 100.0 & 97.4 & (100) & 100.0 & 94.1 & $(100)$ & 100.0 & 100.0 & $(100)$ \\
\hline Flavobacteriales & 50.0 & 100.0 & $(100)$ & 25.0 & 100.0 & $(100)$ & 61.1 & 100.0 & $(100)$ \\
\hline Holophagales & 0.0 & 2.6 & (0) 0.0 & 0.0 & $(0)$ & 0.04 .8 & $(0)$ & & \\
\hline Hydrogenophilales & 0.0 & 2.6 & (0) 0.0 & 5.9 & (0) & 0.00 .0 & (0) & & \\
\hline Lactobacillales & 19.2 & 86.8 & (100) & 37.5 & 82.4 & $(100)$ & 11.1 & 90.5 & $(100)$ \\
\hline Legionellales & 0.0 & 5.3 & (0) 0.0 & 5.9 & (0) & 0.04 .8 & (0) & & \\
\hline Neisseriales & 0.0 & 42.1 & (33.3) & 0.0 & 41.2 & $(50)$ & 0.0 & 42.9 & (0) \\
\hline Oceanspirillales & 0.0 & 7.9 & (0) 0.0 & 5.9 & $(0)$ & 0.09 .5 & $(0)$ & & \\
\hline Pseudomonadales & 69.2 & 100.0 & (100) & 62.5 & 100.0 & $(100)$ & 72.2 & 100.0 & $(100)$ \\
\hline Rhizobiales & 65.4 & 73.7 & $(100)$ & 50.0 & 76.5 & (100) & 72.2 & 71.4 & $(100)$ \\
\hline Rhodobacterales & 3.8 & 7.9 & (0) 0.0 & 5.9 & (0) & 11.1 & 9.5 & $(0)$ & \\
\hline Rhodocyclales & 0.0 & 31.6 & (0) 0.0 & 35.3 & (0) & 0.028 .6 & $(0)$ & & \\
\hline Rhodospirillales & 3.8 & 2.6 & (0) 0.0 & 0.0 & (0) & 11.1 & 4.8 & (0) & \\
\hline Sphingobacteriales & 46.2 & 97.4 & (100) & 50.0 & 94.1 & $(100)$ & 55.6 & 100.0 & $(100)$ \\
\hline Sphingomonadales & 3.8 & 39.5 & (33.3) & 0.0 & 35.3 & $(50)$ & 11.1 & 42.9 & $(0)$ \\
\hline Verrucomicrobiae & 0.0 & 5.3 & (0) 0.0 & 11.8 & (0) & 0.00 .0 & $(0)$ & & \\
\hline Xanthomonadales & 26.9 & 73.7 & (100) & 37.5 & 100.0 & $(100)$ & 22.2 & 100.0 & $(100)$ \\
\hline Total swabs & 26.0 & 38.0 & 3 & 8.0 & 17.0 & 2 & 18.0 & 21.0 & 1 \\
\hline
\end{tabular}


Richard W. Hyman et al. / American Journal of Microbiology 3 (2): 18-30, 2012

Table 7. Bacterial Order total percentages. The percent of the swabs with the bacterial Order supported by $>1 \%$ of the reads as a function of time and location. Time points 1 and 2. Time point 3 was not included because of a paucity of swabs

\begin{tabular}{lcrrr}
\hline & $1 \mathrm{~F}$ & $2 \mathrm{~F}$ & $1 \mathrm{~B}$ & $2 \mathrm{~B}$ \\
\hline Average (\%) & 95.0 & 96.0 & 95.4 & 95.8 \\
SD & 1.0 & 2.4 & 1.5 & 1.7 \\
Number of swabs & 8.0 & 17.0 & 18.0 & 22.0 \\
\hline
\end{tabular}

$\mathrm{F}=$ front of the base of the neck. $\mathrm{B}=$ back of the base of the neck. SD = Standard Deviation

Table 8. Order SDI. The SDI was calculated from the bacterial Order data for each swab

\begin{tabular}{|c|c|c|c|c|c|c|}
\hline Volunteer ID & Winter $1 \mathrm{~F}$ & Summer $2 \mathrm{~F}$ & Winter $3 \mathrm{~F}$ & Winter 1B & Summer 2B & Winter 3B \\
\hline$\overline{01}$ & & & & & 3.71 & \\
\hline 02 & & 2.80 & & & 3.09 & \\
\hline 03 & & & & 1.63 & & \\
\hline 04 & & 3.58 & & & & \\
\hline 05 & 1.75 & 2.64 & & & & 2.53 \\
\hline 06 & & 3.20 & & & & \\
\hline 07 & 1.91 & & & 1.90 & 1.62 & \\
\hline 08 & & & 3.40 & & 3.45 & \\
\hline 09 & & & & & 2.74 & \\
\hline 10 & & & & & 2.74 & \\
\hline 11 & & 3.77 & & & & \\
\hline 12 & & 3.38 & & & & \\
\hline 13 & & 3.70 & & & 3.33 & \\
\hline 15 & 2.20 & & & 1.66 & & \\
\hline 16 & & & & 2.02 & 2.61 & \\
\hline 17 & 1.50 & & & & 3.30 & \\
\hline 18 & & 1.62 & & & & \\
\hline 19 & 1.89 & & & 1.58 & & \\
\hline 22 & & & & & 3.21 & \\
\hline 23 & & & & 2.31 & & \\
\hline 24 & & 2.59 & & & 2.09 & \\
\hline 25 & & & & 1.84 & & \\
\hline 26 & & 3.36 & & & 2.13 & \\
\hline 27 & 1.50 & & & 1.92 & & \\
\hline 28 & & & & 1.71 & & \\
\hline 29 & & 3.34 & & 2.04 & & \\
\hline 30 & 1.39 & & & 2.02 & & \\
\hline 31 & & & & & 2.79 & \\
\hline 32 & & 3.57 & & & 2.78 & \\
\hline 34 & & & & 1.92 & 3.62 & \\
\hline 35 & 1.74 & 1.65 & & 1.62 & 2.27 & \\
\hline 36 & & & & 1.90 & & \\
\hline 37 & & & & 1.88 & 2.95 & \\
\hline 38 & & & 3.17 & 1.88 & 3.34 & \\
\hline 39 & & & & 1.81 & & \\
\hline $\mathrm{a} 40$ & & & & 2.23 & & \\
\hline 51 & & & & & 3.34 & \\
\hline 57 & & 3.21 & & & 2.77 & \\
\hline 58 & & 3.44 & & & & \\
\hline 63 & & 2.26 & & & & \\
\hline 66 & & 3.43 & & & 3.52 & \\
\hline 82 & & & & & 2.90 & \\
\hline No. swabs & 8.00 & 17.00 & 2 & 18.00 & 22.00 & 1.00 \\
\hline Average & 1.74 & 3.04 & & 1.89 & 2.92 & \\
\hline SD & 0.25 & 0.63 & & 0.19 & 0.53 & \\
\hline
\end{tabular}

No. $=$ Number of; $\mathrm{SD}=$ Standard Deviation 
Three additional bacteria Orders were supported by, at least, $1 \%$ of the reads on $>90 \%$ of all of the swabs: Bacillales (98.5\%), Enterobacteriales $(97.0 \%)$ and Burkholderiales $(91.0 \%)$.

The average percentage of each bacterial Order supported by more than $1 \%$ of the reads on each neck swab is given in Table 6. Actinobacteridae were supported by the most reads for $58 \%$ of the swabs, followed by Enterobacteriales $(29 \%)$, followed by Bacillales (10\%), followed by Burkholderiales and Flavobacteriales (both at 1.4\%). (Unfortunately, there were only three swabs with Order data for the third time point: two Front swabs and one Back swab. Therefore, for our further analyses, we ignored the Order data for the third time point.).

The average percentage of sequence reads for each swab supporting a bacterial Order by more than $1 \%$ of the reads is given in Table 7. None of the values was statistically significantly different from the others. For example, the value for $1 \mathrm{~F}(95.0+/-1.0 \%)$ was not statistically significantly different from the value for $2 \mathrm{~F}$ $(96.0+/-2.4 \% ; p=0.27)$. The overall average percentage $(\mathrm{n}=67)$ of each bacterial Order supported by more than $1 \%$ of the reads was $95.7+/-1.8 \%$. This percentage was statistically significantly different $(p<0.00001)$ from the analogous average for the Class data. This difference was not surprising as the reads were spread over 31 Orders compared to 15 Classes.

The SDI was calculated for the Order data for each swab (Table 8). The average values and standard deviations for each group of swabs were also determined and reported in Table 8 . The average SDI for $1 \mathrm{~F}$ was not statistically different from the average SDI for $1 B(p=0.10)$. The average SDI for $2 F$ was not statistically different from the average SDI for $2 \mathrm{~B}$ $(p=0.52)$. In contrast, the average SDI of $1 F$ was statistically significantly different from the average SDI of $2 \mathrm{~F}(\mathrm{p}<0.00001)$ and the average SDI of $1 \mathrm{~B}$ was statistically significantly different from the average SDI of $2 B(\mathrm{p}<0.00001)$.

There were only eight transitions within the Order data: two $1 \mathrm{~F}$ to $2 \mathrm{~F}$ (volunteers 05 and 35 ) and four $1 \mathrm{~B}$ to 2B (volunteers $07,16,34,35,37$ and 38). For six of the eight transitions, the percentage of Actinobacteridae increased substantially, while for all eight transitions the percentage of Enterobacteriales decreased substantially.

\section{CONCLUSION}

The skin microbiome at the base of the front and back of the neck was composed principally of the same five
Classes of bacteria over the course of one year: Actinobacteria, Alphaproteobacteria, Bacilli, Betaproteobacteria and Gammaproteobacteria. We could not distinguish the front microbiome from the back microbiome, nor men from women. However, as demonstrated by SDI and PCA analyses, the skin microbiome at each of the three time points differed from the other two time points. That is, each time a neck swab was taken, the microbiome was unique, not as to the bacteria present but rather the relative percentages of the five principal Classes of bacteria. However, it must be noted that the mix of volunteers was different at each time point.

We chose to investigate the skin microbiome at the front and back of the base of the neck because no one else had published the skin microbiome at these two body sites, nor did we know of anyone else investigating those two sites. That makes comparisons of our results to published data difficult. Nevertheless, some comparisons may be made.

Our two studied skin sites may be classified as sebaceous sites (Kong, 2011). The closest previously studied sebaceous sites are the upper chest and the upper back. (The occiput, the back of the scalp, is not comparable to the nape, as our back swabs were taken below the hairline and the occiput is above the hairline). The microbiome of the upper chest is composed almost entirely of Actinobacteria (Kong, 2011). The microbiome of the upper back is composed principally of Actinobacteria with some Proteobacteria (Grice et al., 2009). These comparisons again emphasize that small differences in skin location may give rise to substantial differences in the composition of the skin microbiome.

There were two important technical limitations in our data collection. The first limitation was the universality of the PCR primers. The PCR primers employed to amplify the V6 hypervariable region of the rDNA may have some mismatches to the rDNAs of relevant bacteria (Soergel et al., 2012; Frank et al., 2008). Presumably, such mismatch resulted in less amplification, especially in the critical first round. The second limitation was the depth of sequencing. A minimum of $1 \%$ of the sequence reads supporting the presence of a bacterium was required to report the presence of that bacterium. The Chao1 analysis (Fig. 1) suggested that there were bacteria present at concentrations below this limit. In addition, scientists working within the Human Microbiome Project have reported some very idiosyncratic results from employing rDNA sequence to identify bacteria (JCHMPDGWG, 2012; Haas et al., 2011). 
It is clear from this and previously published enumerations of the skin microbiome that many skin sites on many people in many geographic areas need to be studied and over a long period of time (Grice and Segre, 2011; Kong, 2011; Gao et al., 2007; Fierer et al., 2008; Costello et al., 2009; Caporaso et al., 2011). A good start has been made, but there is much more to be accomplished (Peterson et al., 2009; HMPC, 2012).

\section{ACKNOWLEDGEMENT}

We thank the 50 volunteers who contributed skin swabs to this study. We thank Monica Trebo for posting the data on the Stanford Genome Technology Center website. This study was supported by Public Health Service grant PO1 HG000205 (R.W.D.) from the National Human Genome Research Institute. All authors declare that they have no financial conflicts of interest.

\section{REFERENCES}

Caporaso, J.G., C.L. Lauber, E.K. Costello, D. BergLyons and A. Gonzalez et al., 2011. Moving pictures of the human microbiome. Genome Biol., 12: R50-R50. DOI: 10.1186/gb-2011-12-5-r50

Caporaso, J.G., J. Kucynski, J. Stombaugh, K. Bittner and F.D. Bushman et al., 2010. QIIME allows analysis of high-throughput community sequencing data. Nat. Methods, 7: 335-336. DOI: 10.1038/nmeth.f.303

Cole, J.R., Q. Wang, E. Cardenas, J. Fish and B. Chai et al., 2009. The ribosomal database project: Improved alignments and new tools for rRNA analysis. Nucl. Acids Res., 37: D141-D145. DOI: 10.1093/nar/gkn879

Colwell, R.K. and J.A. Coddington, 1994. Estimating terrestrial biodiversity through extrapolation. Phil. Trans. Royal Soc. B: Biol. Sci., 345: 101-118. DOI: 10.1098/rstb.1994.0091

Costello, E.K., C.L. Lauber, M. Hamady, N. Fierer and J.I. Gordon et al., 2009. Bacterial community variation in human body habitats across space and time. Science, 326: 1694-1697. DOI: 10.1126/science. 1177486

Dethlefsen, L., S. Huse, M.L. Sogin and D.A. Relman, 2008. The pervasive effects of an antibiotic on the human gut microbiota, as revealed by deep $16 \mathrm{~S}$ rRNA sequencing. PLoS Biol., 6: e280-e280. DOI: 10.1371/journal.pbio.0060280
Fierer, N., M. Hamady, C.L. Lauber and R. Knight, 2008. The influence of sex, handedness and washing on the diversity of hand surface bacteria. Proc. Natl. Acad. Sci. USA., 105: 17994-17999. DOI: 10.1073/pnas.0807920105

Frank, J.A., C.I. Reich, S. Sharma, J.S. Weisbaum and B.A. Wilson et al., 2008. Critical evaluation of two primers commonly used for amplification of bacterial 16S rRNA genes. Applied Environ. Microbiol., 74: 2461-2470. DOI: 10.1128/AEM.02272-07

Gao, Z., C.H. Tseng, Z. Pei and M.J. Blaser, 2007. Molecular analysis of human forearm superficial skin bacterial biota. Proc. Natl. Acad. Sci. U.S.A., 104: 2927-2932. DOI: 10.1073/pnas.0607077104

Grice, E.A. and J.A. Segre, 2011. The Skin Microbiome. Nat. Rev. Microbiol., 9: 244-53. DOI: 10.1038/nrmicro2537

Grice, E.A., H.H. Kong, S. Conlan, C.B. Deming and J. Davis et al., 2009. Topographical and temporal diversity of the human skin microbiome. Science, 324: 1190-1192. DOI: 10.1126/science. 1171700

Haas, B.J., D. Gevers, A.M. Earl, M. Feldgarden, D.V. Ward and G. Giannoukos et al., 2011. Chimeric 16S rRNA sequence formation and detection in Sanger and 454-pyrosequenced PCR amplicons. Genome Res., 21: 494-504. DOI: 10.1101/gr.112730.110

HMPC, 2012. Structure, function and diversity of the healthy human microbiome. Nature, 486: 207-214. DOI: $10.1038 /$ nature 11234

Hughes, J.B., J.J. Hellmann, T.H. Ricketts and B.J.M. Bohannan, 2001. Counting the uncountable: Statistical approaches to estimating microbial diversity. Applied Environ. Micro., 67: 4399-4406. DOI: 10.1128/AEM.67.10.4399-4406.2001

Huse, S.M., L. Dethlefsen, J.A. Huber, D.M. Welch and D.A. Relman et al., 2008. Exploring microbial diversity and taxonomy using SSU rRNA hypervariable tag sequencing. PLoS Genet., 4: e1000255. DOI: 10.1371/journal.pgen.1000255

Hyman, R.W., F. Babrzadeh, C. Palm, C. Wang and M. Fukushima et al., 2012. Bacteria on Human Skin. Am. J. Micro., 2: 25-34. DOI: 10.3844/ajmsp.2011.25.34

Hyman, R.W., M. Fukushima, L. Diamond, J. Kumm and L.C. Giudice et al., 2005. Microbes on the human vaginal epithelium. Proc. Natl. Acad. Sci. U.S.A., 102: 7952-7957. DOI: 10.1073/pnas.0503236102 
JCHMPDGWG, 2012. Evaluation of 16S rDNA-based community profiling for human microbiome research. PLoS One, 7: e39315-e39315. DOI: 10.1371/journal.pone.0039315

Kong, H.H., 2011. Skin Microbiome: Genomics-Based Insights into the Diversity and Role of Skin Microbes. Trends Mol. Med., 17: 320-8. DOI: 10.1016/j.molmed.2011.01.013

Lozupone, C., M.E. Lladser, D. Knights, J. Stombaugh and R. Knight, 2011. UniFrac: An effective distance metric for microbial community comparison. ISME J., 5: 169-172. DOI: 10.1038/ismej.2010.133

Peterson, J., S. Garges, M. Giovanni, P. McInnes and L. Wang et al., 2009. The NIH Human Microbiome Project. Genome Res., 19: 2317-2323. DOI: 10.1101/gr.096651.109

Shannon, C.E., 1948. A mathematical theory of communication. Bell Syst. Tech. J., 27: 379-423.

Soergel, D.A., N. Dey, R. Knight and S.E. Brenner, 2012. Selection of primers for optimal taxonomic classification of environmental 16S rRNA gene sequences. ISME J. DOI: 10.1038/ismej.2011.208
Staudinger, T., A. Pipal and B. Redl, 2011. Molecular analysis of the prevalent microbiota of human male and female forehead skin compared to forearm skin and the influence of make-up. J. Applied Microbiol., 110: 1381-1389. DOI: 10.1111/j.13652672.2011.04991.x

Wang, C., S. Krishnakumar, J. Wilhelmy, F. Babrzadeh and L. Stepanyan et al., 2012. High-throughput, high-fidelity HLA genotyping with deep sequencing. Proc. Natl. Acad. Sci. U.S.A., 109: 8676-8681. DOI: 10.1073/pnas.1206614109

Wang, Q., G.M. Garrity, M.J. Tiedje and J.R. Cole, 2007. Naïve Bayesian classifier for rapid assignment of rRNA sequences into the new bacterial taxonomy. Applied Environ. Microbiol., 73: 52615267. DOI: 10.1128/AEM.00062-07

Wright, E.S., L. Safak Yilmaz and D.R. Noguera, 2012. DECIPHER, a search-based approach to chimera identification for $16 \mathrm{~S}$ rRNA sequences. Applied Environ. Microbiol., 78: 3 717-725. DOI: 10.1128/AEM.06516-11 